\title{
POPULATION STATUS AND SPATIAL DISTRIBUTION OF SALTWATER CROCODILE, CROCODYLUS POROSUS IN THE SUNDARBANS OF BANGLADESH
}

\author{
Md. Abdul Aziz ${ }^{*}$ and Md. Anwarul Islam² \\ Durrell Institute of Conservation and Ecology, School of Anthropology and \\ Conservation, University of Kent, United Kingdom
}

\begin{abstract}
The Saltwater Crocodile, Crocodylus porosus is endangered in Bangladesh, and currently surviving in rivers and channels of the Sundarbans mangrove forest of the country. Very little information is available on this apex predator in the Sundarbans aquatic ecosystem, therefore a survey was carried out to assess population status and their spatial distribution. By surveying approximately $351 \mathrm{~km}$ of rivers of the Bangladesh Sundarbans during daytime between 2014 and 2015, a total of 42 individual crocodiles were recorded, with an overall encounter rate of 0.12 crocodiles $(\mathrm{SE}=0.02,95 \% \mathrm{CI}=0.08-0.18)$ per $\mathrm{km}$ of rivers. Based on this estimate, it is inferred that a population of approximately 140 crocodiles $(95 \%$ CI $=90-190)$ could occur in the Bangladesh Sundarbans. The generalised linear model revealed statistically insignificant negative relationship of relative crocodile abundance with the salinity level $(\beta=-0.067$, SE $=0.057, \mathrm{p}=0.242)$ and protection status $(\beta=-0.208, \mathrm{SE}=0.855, \mathrm{p}=0.808)$, and statistically insignificant positive relationship with the distance to human habitations $(\beta=0.004, \mathrm{SE}=0.039, \mathrm{p}=0.914)$. Disturbance by resource collectors, cargo vessels, and water pollution are the major threats to crocodile populations of the Sundarbans. The results of this study will be useful in future population monitoring to guide conservation management of saltwater crocodile in this important habitat.
\end{abstract}

Key words: Distribution, encounter rate, relative abundance, salinity, threats

\section{INTRODUCTION}

The family Crocodylidae is represented by the 24 living species of alligators, caimans, crocodiles and gharials (Martin 2008). They principally live in the tropical and subtropical aquatic habitats ranging from forest streams, rivers, marshes and swamps to salty waters of mangroves or estuaries (Dunson 1982, Mazzotti and Dunson 1984). Bangladesh is the home to three species of crocodiles; the Marsh crocodile (Crocodylus palustris), the Saltwater Crocodile (Crocodylus porosus) and the Gharial (Gavialis gangeticus). Unfortunately, the Marsh crocodile was extirpated in the Sundarbans during the 1980s and the last known individual that survived in the shrine of Khan Jahan Ali at Bagerhat (approximately $25 \mathrm{~km}$ north of the Sundarbans) for several decades, died in

*Author for correspondence: <maaziz78@gmail.com>. 'Present address: Department of Zoology, Jahangirnagar University, Savar, Dhaka-1342, Bangladesh. 2Department of Zoology, University of Dhaka, Dhaka-1000, Bangladesh.

() 2018 Zoological Society of Bangladesh DOI: http://dx.doi.org/10.3329/bjz.v46i1.37624 
2014. There could be some remnant Gharial populations surviving in relatively wide rivers across north-western regions of the country but their population status remains largely unknown. The saltwater crocodile is endangered while the Gharialis critically endangered in Bangladesh (IUCN Bangladesh 2015), which have been listed in the Appendix I of the CITES (Convention on International Trade in Endangered Species), and protected by the Bangladesh Wildlife (Protection and Security) Act, 2012 (MoEF 2012).

The saltwater crocodile is the top predator of aquatic ecosystems of the Sundarbans mangrove landscapes. In the past, the saltwater crocodile was abundant across the southern coast of Bangladesh but heavy exploitation for skins until 1970s greatly depleted its population (Whitaker 1982). The endangered saltwater crocodile received very little attention in previous investigations, thus very little data, a side a few anecdotal reports (Tamang 1993, Hussain and Achargya 1994), are available on their population status and distribution in the Sundarbans (Halder and Deodatus 2003). Population abundance and patterns of distribution in relation to habitat characteristics are vital to future management of this poorly known species.

The Sundarbans is the largest single block of halophytic mangrove forest in the world, with a total area of $10,000 \mathrm{~km}^{2}$ shared between Bangladesh and India (Seidensticker and Hai 1983). The Sundarbans has vegetated low lying islands with elevations ranging from $0.9 \mathrm{~m}$ to $2.1 \mathrm{~m}$ above the mean sea level (Iftekhar and Islam 2004). The climate is humid with marked seasonality of weather patterns and average annual rainfall from about $1,800 \mathrm{~mm}$ in Khulna near the north of the Sundarbans to $2,790 \mathrm{~mm}$ on the coast with the majority of rainfall (70 - 80\%) during monsoon (August-September). Annual temperature varies from $20^{\circ} \mathrm{C}$ in December-January to $34^{\circ} \mathrm{C}$ in June-July with a range of about $8^{\circ} \mathrm{C}$ (Islam 2008). Tropical storms and cyclones produce large water level rises with tidal waves up to $7.5 \mathrm{~m}$ recorded (Seidensticker and Hai 1983). Tides and storm surges result in regular inundation of the low-lying islands (Iftekhar and Islam 2004).

The Sundarbans has formed an estuary between the freshwater discharged by rivers originating from the Ganges and the influx of saline water from the Bay of Bengal. As a result, the water salinity varies seasonally and spatially in relation to the volume of freshwater coming from the upstream rivers and intermittent tidal cycles of the Bay of Bengal. Generally, daily salinity peak at the coast is influenced by the arrival of high water from the sea (Wahid et al. 2007). Ecological and habitat features including nesting suitability, human activities and habitat degradation can play important role on the occurrence of crocodiles (Read et al. 2004). Therefore, assessing habitat features such as 
salinity, and level of protection and proximity to human habitations that could influence saltwater crocodile distribution may provide critical insight into their spatial ecology in the Sundarbans.

The objectives of this study were therefore to assess population status, and to understand the spatial distribution of the saltwater crocodile across the Bangladesh Sundarbans. Representative sample areas were surveyed which demonstrated an approach to investigate population status and spatial occurrence of the saltwater crocodile in the mangrove ecosystem.

\section{MATERIAL AND METHODS}

The Sundarbans within the territory of Bangladesh covers $6,017 \mathrm{~km}^{2}$, of which $1,874 \mathrm{~km}^{2}(30 \%)$ constitute water bodies comprising interconnecting rivers, creeks and canals (Chaffey et al. 1985, Hussain and Achargya 1994). The Sundarbans is managed as a Reserved Forest by the Bangladesh Forest Department and three isolated areas have been delineated as Wildlife Sanctuary (WS) : The Sundarbans West WS $\left(715 \mathrm{~km}^{2}\right)$, Sundarbans South WS $\left(370 \mathrm{~km}^{2}\right)$, and Sundarbans East WS $\left(383 \mathrm{~km}^{2}\right)$ (Fig. 1). These WS were collectively declared a UNESCO World Heritage Site in 1997 (Iftekhar and Islam 2004). Very recently, three river-based WS were established for the protection of cetaceans: Chandpai $\left(5.6 \mathrm{~km}^{2}\right)$, Dudhmukhi $\left(1.7 \mathrm{~km}^{2}\right)$, and Dhangmari $\left(3.4 \mathrm{~km}^{2}\right)$ (Bangladesh Forest Department 2017).

Salinity condition of the Sundarbans is strongly influenced by the volume of freshwater flow from the upstream rivers and nature of tide from the Bay of Bengal (Wahid et al. 2007). Daily peak salinity in the southern coastal regions of the forest coincides with the arrival of water during high tide; however the daily range of salinity levels varies with season. Salinity generally increases from east to west during monsoon (August - September) and from northeast to southeast at rest of the months (Siddiqi 2001, Wahid et al. 2007). Salinity level along the northern part of Sundarbans ranges from 1 to $9 \mathrm{ppt}$ (parts per thousand) in the monsoon (August - September) and post monsoon (October - November) but it may increase up to 24 ppt during dry season (February - May) (Siddiqi 2001, Wahid et al. 2007). Overall, about 60\% of the area, mostly in the western part of the Bangladesh Sundarbans contains salinity level of $>20$ ppt at least one and a half months a year (Wahid et al. 2007). Four sample areas were surveyed that covered areas of different salinity gradients of the Bangladesh Sundarbans (Fig. 1). Due to logistical constraints we could not measure the level of salinity at sample points; instead, long-term salinity data from Wahid et al. (2007) were used in analysis. 


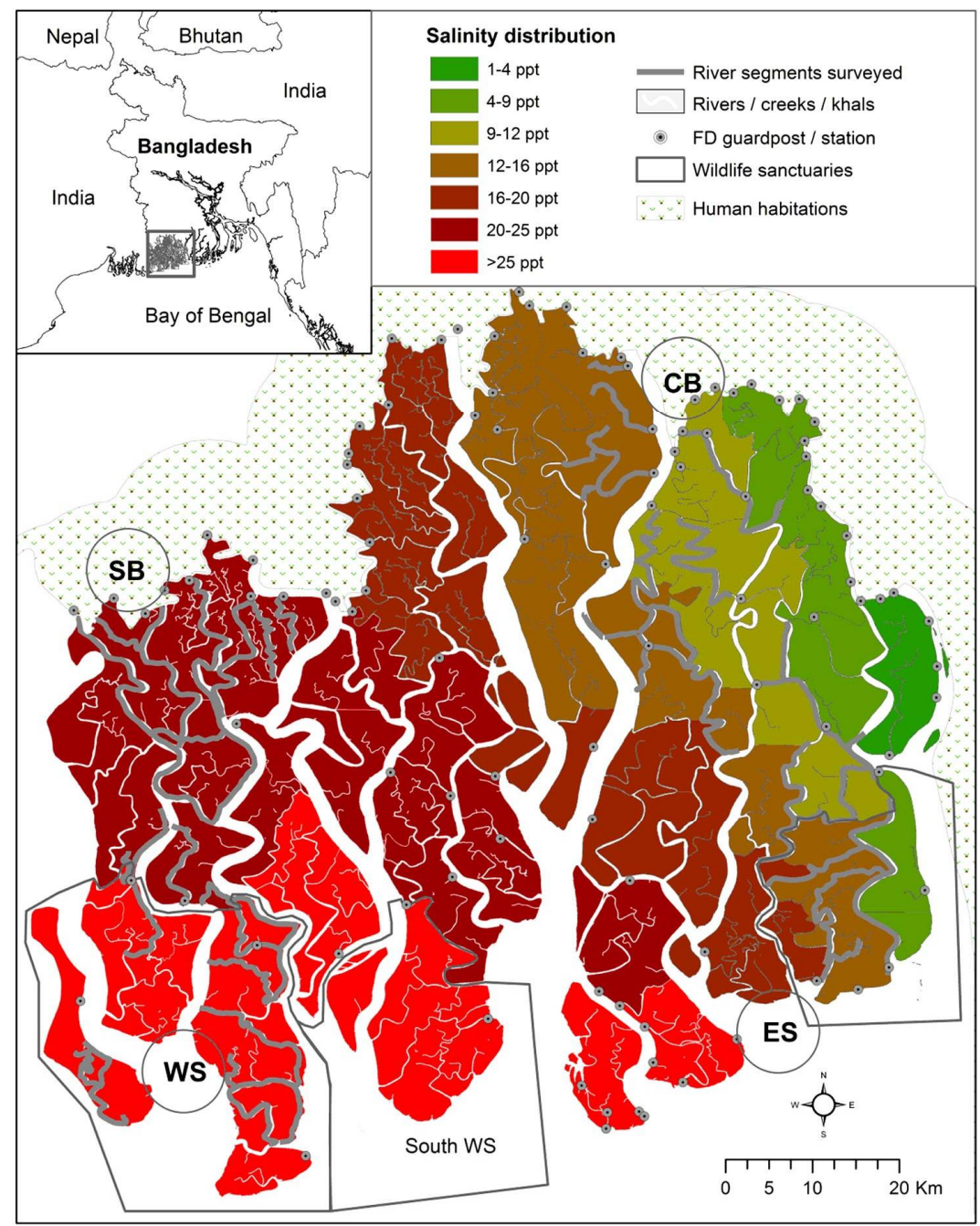

Fig. 1. The Bangladesh Sundarbans showing salinity gradients, segments of rivers surveyed, including three wildlife sanctuaries and four sample areas, indicated by SB = Satkhira Block, WS = West Wildlife Sanctuary, CB = Chandpai Block, and ES = East Wildlife Sanctuary. Salinity gradients (April) were plotted approximately using data from Wahid et al. (2007).

Four sample areas were selected, totalling $1,994 \mathrm{~km}^{2}$, for this survey, including Satkhira block, SB (342 km²), West Wildlife Sanctuary, WS $\left(715 \mathrm{~km}^{2}\right)$, East Wildlife Sanctuary, ES $\left(383 \mathrm{~km}^{2}\right)$, and Chandpai block, CB $\left(554 \mathrm{~km}^{2}\right)$ (Fig. 1). The level of protection, human use, and location were considered in selecting these sample areas. The west WS and east WS have high level of protection and are away from human settlement, while SB and CB are reserve forest and near to human habitation. Extraction of forest and aquatic resources are usually permitted from reserve forest areas but not from the sanctuaries. From these 
four sample areas, we surveyed 47 river segments comprising $351 \mathrm{~km}$, where survey segments ranged from 4 to $21 \mathrm{~km}$. Rivers which were $100 \mathrm{~m}$ to $1 \mathrm{~km}$ wide were considered for this survey allowing reliable recording of crocodiles and better navigation.

Between November, 2014 and March, 2015, surveys were conducted mostly during low-tide to increase chances of spotting basking crocodiles (Choudhary and Roy1982). Night survey was avoided due to fear of tiger attack within narrow creeks and security issues in the Sundarbans. Five survey teams were deployed with four members in each team comprising one data recorder, two observers to spot on the either side of river and one member for guiding the survey team. Each sample area was surveyed at one time and repeatedly surveyed each river segment two to six times. The sample block SB was surveyed from 20 November to 11 December, 2014 and WS from 17 to 30 December in 2014 and ES and CB from 4 to 26 February, 2015. The location of each crocodile was recorded using handheld GPS Garmin GPSMAP 64 and noted down approximate size ( $\sim 3.5 \mathrm{~m}$ and above as adult and rest as non-adult) of the crocodile sighted and related habitat characteristics (e.g., vegetation and slope of mudflat on the river edge) in the data sheet.

Crocodile encounter rate was calculated as individuals detected per $\mathrm{km}$ river segment surveyed, with 95\% confidence intervals (CI). Using the individual relative abundance estimates, ageneralized linear model was run with crocodile abundance as response variable and levels of salinity, distance to human habitations $(\mathrm{km})$ and level of protection (sanctuary versus reserve forest) as predictors. This set of predictors was considered to investigate whether they influence the spatial occurrence of the saltwater crocodiles. The distance to human habitations for each survey transect to the nearest human settlements was measured using Arc GIS v 10.3. All statistical analyses were performed in R language environment ( $\mathrm{R}$ Core Team 2016) and prepared map using Arc GIS v10.3.

\section{RESULTS AND DISCUSSION}

Approximately $97 \mathrm{~km}$ rivers from the SB, $78 \mathrm{~km}$ from WS, $101 \mathrm{~km}$ from ES, and $75 \mathrm{~km}$ from CB sample areas have been surveyed for this study (Table 1). During the survey, a total of 42 individual crocodiles were recorded with an overall relative abundance estimate of $0.12(\mathrm{SE}=0.02,95 \% \mathrm{CI}=0.08-0.18)$ individual per $\mathrm{km}$ of river. This estimate translates into approximately one individual of crocodile in every $8.35 \mathrm{~km}$ of rivers surveyed. Using this estimate, a population between 30 and 63 crocodiles $(95 \% \mathrm{CI})$ was extrapolated for the areas sampled. Based on the survey coverage (sample areas covered approximately $33 \%$ of the Bangladesh Sundarbans), it was inferred that a population of 
approximately 140 adult crocodiles $(95 \% \mathrm{CI}=90$ - 190) could occur in the entire Bangladesh Sundarbans. The majority of our sightings were adult $(\mathrm{n}=39)$ and the remaining non-adults $(n=3)$.

\begin{tabular}{|c|c|c|c|c|c|}
\hline $\begin{array}{l}\text { Sample } \\
\text { area }\end{array}$ & $\begin{array}{l}\text { Area } \\
\left(\mathrm{km}^{2}\right)\end{array}$ & $\begin{array}{l}\text { Protection } \\
\text { status }\end{array}$ & $\begin{array}{l}\text { Number of river } \\
\text { segments surveyed }\end{array}$ & $\begin{array}{c}\text { Rivers } \\
\text { surveyed } \\
(\mathrm{km})\end{array}$ & $\begin{array}{c}\text { No. of } \\
\text { crocodiles } \\
\text { detected }\end{array}$ \\
\hline Satkhira Block & 342 & $\begin{array}{l}\text { Reserve } \\
\text { forest }\end{array}$ & 10 & 97 & 2 \\
\hline West Wildlife Sanctuary & 715 & $\begin{array}{l}\text { Protected } \\
\text { area }\end{array}$ & 12 & 78 & 6 \\
\hline Chandpai Block & 544 & $\begin{array}{l}\text { Reserve } \\
\text { forest }\end{array}$ & 14 & 75 & 19 \\
\hline East Wildlife Sanctuary & 383 & $\begin{array}{l}\text { Protected } \\
\text { area }\end{array}$ & 11 & 101 & 15 \\
\hline
\end{tabular}

Although the population estimates of this study came from an opportunistic survey, these results are robust because we systematically surveyed larger spatially representative sample areas. However, our population estimates are probably highly skewed towards the adult crocodiles (93\%) which are most likely to be seen during the day than at night (Thorbjarnarson et al. 2000). A six-year study that surveyed $4,174 \mathrm{~km}$ waterways in Gueensland, Australia reported $33 \%$ of non-adults C. porosus in their estimates (Read et al. 2004). Therefore our population estimates has probably missed out a good proportion of non-adult crocodiles due to surveys limited to day time only. However, other studies show that pristine populations of crocodiles which typically have a high rate of juvenile mortality (Webb and Manolis 1989) should be dominated by reproductively adult animals where juveniles should be represented in comparatively low numbers. Age-based population estimates of $C$. porosus are lacking for the Sundarbans of Bangladesh; yet several previous studies have revealed a range of population estimates between 10 (Tamang 1993) and 200 individuals (Hussain and Acharya 1994), which were considered largely hypothetical because the estimates provided were not based on any systematic surveys (Halder and Deodatus 2003). A study has reported that the crocodile population of the Sundarbans could have suffered a population size bottleneck due to heavy commercial hunting before 1970s and the current population might be recovering slowly after banning commercial exploitation (Whittaker 1982). 
The generalized linear model showed insignificant negative relationships between relative abundance of crocodiles and salinity $(\beta=-0.067, \mathrm{SE}=0.057$, $\mathrm{p}=0.242)$, and level of protection $(\beta=-0.208, \mathrm{SE}=0.855, \mathrm{p}=0.808)$. A positive insignificant $(\beta=0.004, \mathrm{SE}=0.039, \mathrm{p}=0.914)$ relationship was found between relative abundance of crocodiles and the distance to human habitations (Table 2).

Table 2. Predictors associated with the distribution of saltwater crocodile using generalised linear model fit to Poisson distribution

\begin{tabular}{llllll}
\hline Response & Predictors & $\beta$ & SE & $Z$ value & $\operatorname{Pr}(>|z|)$ \\
\hline $\begin{array}{l}\text { Occurrence of saltwater } \\
\text { crocodiles }\end{array}$ & Intercept) & -0.266603 & 1.271133 & -0.21 & 0.834 \\
& $\begin{array}{l}\text { Salinity } \\
\text { Distance to human } \\
\text { habitations }\end{array}$ & -0.004297 & 0.039699 & 0.108 & 0.914 \\
& Level of protection & -0.208246 & 0.855302 & -0.243 & 0.808 \\
\hline
\end{tabular}

No significant associations were found between crocodile relative abundance and levels of salinity, protection status and distance to human habitations of the sample areas. However, it is interesting to note that low saline areas were preferred by crocodiles even being close to the human habitations. Also, higher protection in the sanctuaries literally has no influence on crocodile occurrence which again might be due to the higher level of salinity on the coast. According to Read et al. (2004) the distribution and abundance of C. porosus in Queensland were found to be varied in relation to the availability of nesting habitat, including other confounding factors of commercial fishing, habitat degradation and modification. In addition to the model predictors that we used, the scale of resource extraction, intensity of navigations by commercial vessels, vegetation types, and elevation of the forest floor may influence the habitat preference of crocodiles in the Sundarbans. It was therefore recommended that the larger sample sizes of survey transects including data on full ranges of seasonal salinity, and human activities (e.g., fishing, commercial navigation, etc.) and habitat characteristics (e.g., elevation, vegetation types) can be modelled in future investigations to better explain the patterns of crocodile distribution in the Sundarbans.

Two feeding events were recorded during the survey that are of anecdotal interest. In the first instance, we found an adult crocodile feeding on spotted deer (Axis axis) carcases on the bank of a river and in the second event found evidence that a crocodile predated a spotted deer from a swampy area of forest and dragged it down to the nearby river. Additionally, we found that $97 \%$ of detected crocodiles were basking on the exposed muddy bank of rivers between 0900 and 1600 hrs during low tide period (Fig. 2a). 

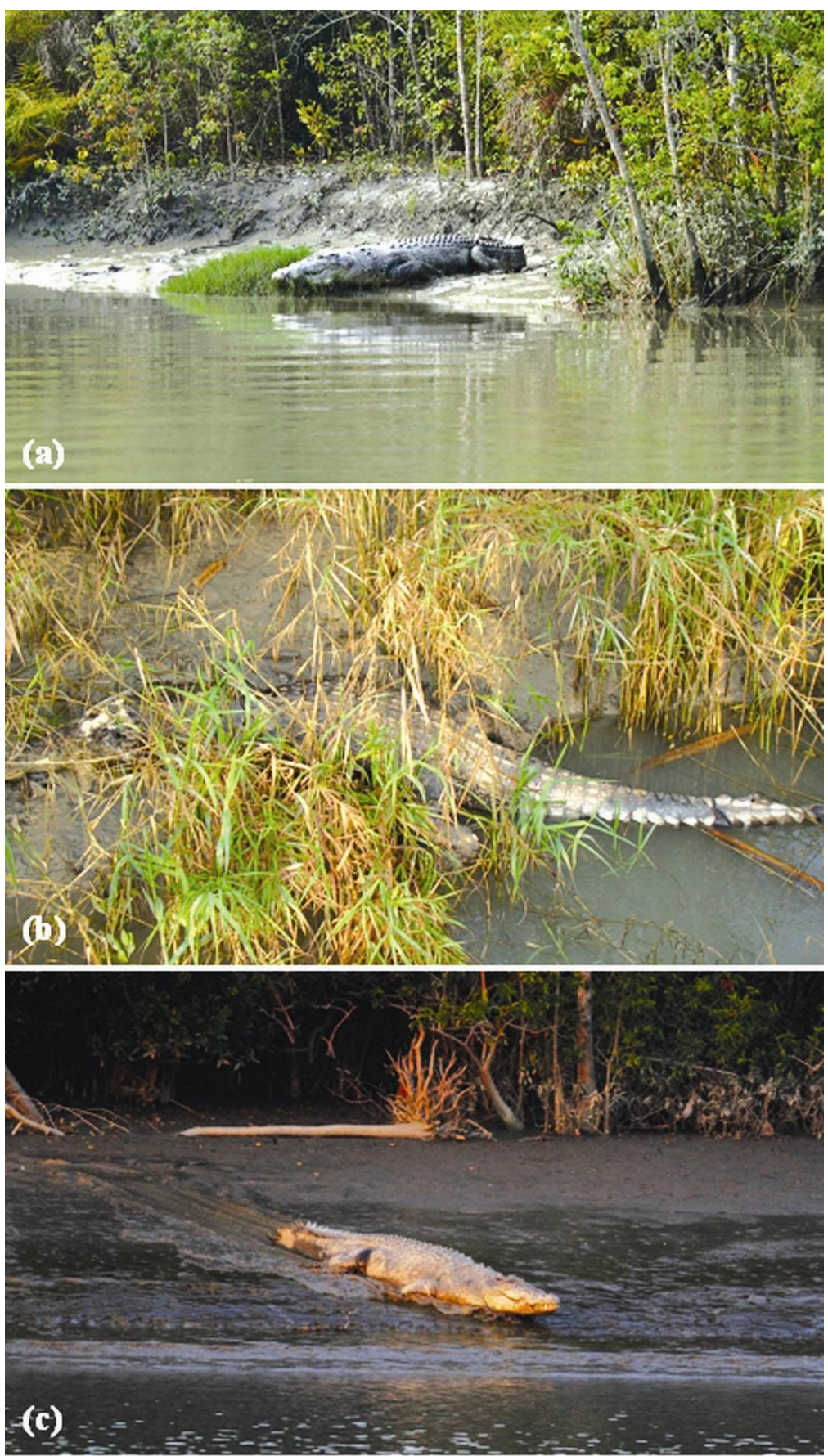

Photograph (C) M. A. Aziz

Fig. 2. Saltwater crocodiles in the Bangladesh Sundarbans: (a) a crocodile basking on a river bank, (b) Dead crocodile found in the eastern region, (c) crocodile smeared with furnace oil spilled from a capsized vessel. 
Large scale commercial exploitation for crocodile skins up to the 1970s depleted the saltwater crocodile population in Bangladesh (Whitaker 1982, Tamang 1993). Currently, the saltwater crocodile is a protected species by the Wildlife (Protection and Security) Act 2012 in the country but the remaining populations face a range of anthropogenic threats in the Sundarbans similar to other threatened species in this landscape. It is unlikely that crocodiles would have been ignored by poachers due to their valuable skins, though they are conspicuously absent from trafficking involving Bengal tiger and spotted deer (Aziz et al. 2013 and 2017) and a previous report indicated that crocodile hunting might have been occurring in the Sundarbans (Halder and Deodatus 2003). During this study, one crocodile was found dead in the eastern part of the Sundarbans but the cause of its death remained unknown (Fig. 2b). Although regular hunting and eating of saltwater crocodile were reported in Sri Lanka (Gramentz 2008), this activity would probably be a rare phenomenon among communities living next to the Sundarbans because of the previous studies on wildlife hunting (Jagrata Juba Shangha 2003), illegal consumption of deer meat (Mohsanin et al. 2013) and tiger and tiger prey poaching (Aziz et al. 2013 and 2017) in and around the Sundarbans have not found any evidence by chance of hunting and eating crocodile meat by local communities. It is however difficult to confirm without any further evidence that crocodile hunting is completely lacking in the Sundarbans even being reported elsewhere (Gramentz 2008).

The second most significant threat is the disturbance by the large numbers of resource collectors (e.g., Nypapalm harvesting, extensive fishing, honey collection, etc.) and cargo vessels navigating through different channels within the Sundarbans. Reports show that approximately 3.5 million local people enter the forest annually for collecting fish, crabs, honey and non-timber forest products (Hoq 2007). Fishing using a range of fishing nets guided by boats is common place year round while harvesting Nypapalm is limited to winter months when crocodiles relatively heavily bask on river banks. In Myanmar, saltwater crocodiles were known to be entangled in fishing nets that caused a significant proportion of incidental mortality in addition to creating disturbance to the habitat (Platt and Thorbjarnarson 1997, Thorbjarnarson et al. 2000). Although there were no reports of incidental mortality by fishing nets in the Sundarbans, previous studies reported serious disturbance to crocodiles by widespread fishing activities (Halder and Deodatus 2003). Disruption of basking behaviour was particularly noticed in the presence of fishermen and Nypapalm collectors who used small rivers and creeks during their activities. For example, in the $\mathrm{CB}$ areas several individuals of crocodiles disappeared from their regularly 
used basking spots when resource collectors have started Nypapalm harvesting in proximity. In Sri Lanka, Gramentz (2008) noted disturbance as a potential threat to the saltwater crocodile. The cargo vessels and trawlers that move through several major river channels (mainly east and middle parts) of the Sundarbans produce high-pitched sound (e.g., whistle) during their movement, which in turn may disrupt the basking behaviour (Gramentz 2008).

Water pollution related to recent cargo accidents may be one of the pressing agents affecting crocodiles in the Sundarbans (Aziz 2017). For example, cargo vessels carrying furnace oil (350,000 liter), chemical fertilizer containing potash (300 ton), and coal (1,235 ton) were capsized between 2014 and 2016 at Sela Gang in the eastern part of Sundarbans. It is likely that this level of pollution might have adversely affected crocodiles, and their aquatic prey species. One crocodile was found smeared with furnace oil from an oil tanker accident in January, 2015 (Fig. 2c).

Given the substantial previous lack of reliable population and ecological information on this locally endangered crocodile species, results from this study will be useful for future population monitoring. However, it is plausible that the year-round surveys during the day and at night may provide more insight about the precise population size, age structure and spatial distribution of saltwater crocodiles in the Sundarbans mangrove habitat. For immediate management interventions, we recommend to limit resource extractions and cargo navigations along the north-eastern parts of the Sundarbans that have higher relative abundance of crocodiles, which in turn may expedite the population recovery of saltwater crocodiles in the Sundarbans.

Acknowledgments: This study would not have been possible without the financial support from many donors including Panthera, Commonwealth Scholarship Commission, UK, and USAID's Bagh Activity implemented by WildTeam. We particularly thank Mr. Mohammad Shamsuddoha and Professor Jim Groombridge for their support during the work. We also acknowledge the collective effort of the tiger survey team comprising local honey collectors and fishermen. We are thankful to the Bangladesh Forest Department for giving permission to do the research work in the Sundarbans and for providing local support. The comments from two anonymous reviewers helped improve the quality of the manuscript.

\section{LITERATURE CITED}

AZIZ, M.A. 2017. Population, threats and evolutionary conservation genetics of Bengal tigers in the Sundarbans of Bangladesh. Ph.D. Thesis, University of Kent, UK. 252 pp. 
AZIZ, M.A., BARLOW, A.C.D., GREENWOOD, C.C. and ISLAM, M.A. 2013. Prioritizing threats to improve conservation strategy for the Tiger Pantheratigris in the Sundarbans Reserve Forest of Bangladesh. Oryx $b$ 47: 510-518.

AZIZ, M.A., TOLLINGTON, S., BARLOW, A.C.D., GOODRICH, J., SHAMSUDDOHA, M., ISLAM, M.A. and GROOMBRIDGE, J.J. 2017. Investigating patterns of tiger and prey poaching in the Bangladesh Sundarbans: Implications for improved management. Global Ecology and Conservation 9: 70-81.

BANGLADESH FOREST DEPARTMENT. 2017. Protected Area: Wildlife Sanctuary. Available at http://www.bforest.gov.bd/site/page/f619019f-14cd-481a-86f4-1d5b4ae40515/wildlife santuary.

BARLOW, A.C.D. 2009. The Sundarbans tiger: evolution, population status and conflict managment. Ph.D. Thesis, University of Minnesota, Minnesota, USA. 205 pp.

CHAFFEY, D.R., MILLER, F.R. and SANDOM,J.H. 1985. A forestry inventory of the Sundarbans, Bangladesh. Overseas Development Administration, Surrey, England. 196 pp.

CHOUDHARY, B.C. and ROY, R.K. 1982. Status survey of the crocodile population - A field guide. Central Crocodile Breeding and Management Training Institute, Andhra Pradesh, India.

DUNSON, W.A. 1982. Salinity relations of crocodiles in Florida Bay.Copeia 2: 374-385.

GRAMENTZ, D. 2008. The distribution, abundance and threat of the Saltwater Crocodile Crocodylus porosus in the Bentota Ganga, Sri Lanka. 16 pp.

HALDER, N.K. and DEODATUS, F. 2003. Crocodile conservation plan of the Sundarbans. Sundarbans Biodiversity Conservation Project. Asian Development Bank and Bangladesh Forest Department, Dhaka, Bangladesh. 31 pp.

HOQ, M.E. 2007. An analysis of fisheries exploitation and management practices in Sundarbans mangrove ecosystem, Bangladesh. Ocean and Coastal Management 50: 411-427.

HUSSAIN, Z. and ACHARYA,G. 1994. Mangroves of the Sundarbans, Vol. II: Bangladesh. First edition, IUCN, Bangkok, pp. 257

IFTEKHAR, M.S. and ISLAM,M.R. 2004. Degeneration of Bangladesh's Sundarbans mangroves: a management issue. The International Forestry Review 6:123-135.

ISLAM, S.N. 2008. Cultural landscape changing due to anthropogenic influences on surface water and threats to mangrove wetland ecosystems: a case study on the Sundarbans, Bangladesh. Ph.D. thesis, Brandenburg University of Technology at Cottbus, Germany. $179 \mathrm{pp}$.

IUCN BANGLADESH. 2015. Red List of Bangladesh, Volume 2: Mammals. IUCN, International Union for Conservation of Nature, Bangladesh Country Office, Dhaka, Bangladesh, pp. 232.

JAGRATA JUBA SHANGHA, 2003. Human-wildlife Interaction Study. Sundarbans Biodiversity Conservation Project, Dhaka, Bangladesh. 99 pp.

KHAN, M.M.H. 2004. Ecology and Conservation of the Bengal tiger. Ph.D. Thesis, University of Cambridge, Cambridge, UK. 297 pp.

MARTIN, S. 2008. Global diversity of crocodiles (Crocodilia, Reptilia) in freshwater. Hydrobiologia 595: 587-591.

MAZZOTTI, J. and DUNSON,W.A. 1984. Adaptations of Crocodylusacutus and Alligator for life in saline water. Comparative Biochemistry and Physiology 79: 641-646.

MoEF. 2012. The Bangladesh Wildlife (Protection and Security) Act, 2012. Bangladesh Forest Department, Ministry of Environment and Forests, Government of Bangladesh.

MOHSANIN, S., BARLOW, A.C.D, GREENWOOD, C.J., ISLAM,M.A., KABIR, M.M., RAHMAN, M.M.and HOWLADER, A. 2013. Assessing the threat of human consumption of tiger prey in the Bangladesh Sundarbans. Animal Conservation 16: 69-76. 
PLATT, S.G. and THORBJARNARSON,J.B. 1997.Status and Life History of the American Crocodile in Belize. Belize Coastal Zone Management Project BZE/92/G31.United Nations Development Programme, Global Environmental Facility, Belize City and New York.

R Core Team. 2016. R: A language and environment for statistical computing. R Foundation for Statistical Computing, Vienna, Austria.

READ, M.A., MILLER, J.D., BELL, I.P. and FELTON,A. 2004. The distribution and abundance of the saltwater crocodile, Crocodylus porosus, in Gueensland. Wildlife Research 31: 527-534.

SEIDENSTICKER, J. and HAI, M.A. 1983. The Sundarbans Wildlife Management Plan: Conservation in the Bangladesh Coastal Zone. International Union for Conservation of Nature and Natural Resources. Gland, Switzerland. 129 pp.

SIDDIQI, N.A. 2001. Mangrove Forestry in Bangladesh. First edition, Institute of Forestry and Environmental Sciences, University of Chittagong, Chittagong, Bangladesh. 201 pp.

TAMANG, K. M. 1993. Wildlife management plan for the Sundarbans reserved forest. Integrated Resource Development of the Sundarbans Reserved Forest, Bangladesh. 118 pp.

THORBJARNARSON, J., PLATT, S.G. and KHAING, U.S.T. 2000. A population survey of the estuarine crocodile in the Ayeyarwady Delta, Myanmar. Oryx 34: 317-324.

WAHID, S.M., BABEL, M.S. and BHUIYAN,A.R. 2007. Hydrologic monitoring and analysis of the Sundarbans mangrove ecosystem, Bangladesh. J. Hydrology 232: 381-395.

WEBB, G.J.W. and MANOLIS,S.C. 1989. Crocodiles of Australia. Reed Books, Sydney.

WHITTAKER, R. 1982. Exports prospects from commercial crocodile farms in Bangladesh. International Trade Centre, UNCTAD/GATT, ITC/DIP/63, Mission Report. 